\title{
Prognostic effect of neutrophil-lymphocyte ratio during concurrrent chemo-radiotherapy period in glioblastoma patients who did not receive dexamethasone
}

\author{
Kadri Altundag ${ }^{1}$ (D)
}

Received: 23 March 2017 / Accepted: 22 October 2017 / Published online: 31 October 2017

(C) Springer Science+Business Media, LLC 2017

To the Editor,

I want to congratulate Mason et al. [1] for their study. They investigated whether change in neutrophil-lymphocyte ratio (NLR) during focal radiotherapy and concomitant temozolomide (RT-TMZ) provides further prognostic information in glioblastoma. They reported that a decrease in NLR during RT-TMZ is an independent prognostic factor for survival in GBM. One of the variables that may affect the NLR is dexamethasone use in the treatment period. Although authors gave information about the median baseline dexamethasone and median time weighted mean dexamethasone doses, they did not describe number of the patients with GBM who did not receive dexamethasone during concurrent chemoradiotherapy period. Dexamethasone is known to produce a neutrophilia with suppression of neutrophil apoptosis [2]. Therefore, It is hypothesized that dexamethasone may affect NLR ratio. Taken all together, prognostic effect of NLR in patients who did not receive dexamethasone during focal RT-TMZ period may be evaluated separately.

Compliance with ethical standards

Conflict of interest The author indicated no potential conflicts of interest.

\section{References}

1. Mason M, Maurice C, McNamara MG, Tieu MT, Lwin Z, Millar BA, Menard C, Laperriere N, Milosevic M, Atenafu EG, Mason W, Chung C (2017) Neutrophil-lymphocyte ratio dynamics during concurrent chemo-radiotherapy for glioblastoma is an independent predictor for overall survival. J Neurooncol. doi:10.1007/ s11060-017-2395-y

2. Ruiz LM, Bedoya G, Salazar J, de Garcia OD, Patino PJ (2002) Dexamethasone inhibits apoptosis of human neutrophils induced by reactive oxygen species. Inflammation 26(5):215-222
Kadri Altundag

altundag66@yahoo.com

1 MKA Breast Cancer Clinic, Tepe Prime, Cankaya, 06800 Ankara, Turkey 